\title{
A New Method of Fighting Wildfires
}

\author{
Frank R. Tangherlini \\ San Diego, CA, USA \\ Email: frtan96@gmail.com
}

How to cite this paper: Tangherlini, F.R. (2021) A New Method of Fighting Wildfires. Open Journal of Safety Science and Technology, 11, 27-33.

https://doi.org/10.4236/ojsst.2021.112003

Received: November 19, 2020

Accepted: May 31, 2021

Published: June 3, 2021

Copyright $\odot 2021$ by author(s) and Scientific Research Publishing Inc. This work is licensed under the Creative Commons Attribution International License (CC BY 4.0).

http://creativecommons.org/licenses/by/4.0/

\begin{abstract}
It is proposed that in addition to the current method of fighting wildfires that are based on firefighters on the ground, and airdrops, there is the need for a supplemental approach based on using catapults to hurl containers of water at the fires. This additional source of water would serve to extinguish wildfires more rapidly, and thereby reduce the devastation and loss of life they cause, and also reduce the huge amounts of $\mathrm{CO}_{2}$ they pour into the atmosphere that contributes significantly to global warming. Importantly, the use of catapults would result in much greater safety for firefighters on the ground, as well as those serving in the air.
\end{abstract}

\section{Keywords}

Wildfires, Catapults, Reduced Losses, $\mathrm{CO}_{2}$ Reduction, Firefighter and Airdrop Safety

\section{Introduction}

Some years ago, because of the outbreak of wildfires near where I live in San Diego, California, I was led to consider whether there could be any new methods of fighting wildfires that would reduce the time to extinguish them, and thereby reduce the devastation and loss of life they cause. Eventually, I recognized that the present method of fighting wildfires is analogous to a military engagement, with the wildfires analogous to the enemy, the firefighters on the ground analogous to the infantry, and the helicopters and fixed-wing aircraft used in airdrops of water and fire-retardants analogous to the air force. This observation led to the recognition that there is something missing in our present method of fighting wildfires: the artillery! This in turn suggested that perhaps one can improve the present method by introducing equipment that could play the role of artillery, and because this would lead to the ability to pour more water onto the wildfires, it would reduce the time to extinguish them, and hence would help to achieve the desired reduction in losses they cause. 


\section{Methodology and Benefits}

To serve as artillery, I proposed the use of catapults that would be employed to hurl containers of water at the fires. This proposal was published as a Community Essay in the San Diego Union Tribune [1]. Before going into details about what form the catapult system might take, I believe it is important to describe some of the numerous benefits such a system would have.

1) It would enable the firefighters on the ground to attack the wildfires more safely than at present. In particular, a battery of catapults could lay down a barrage of water ahead of the advancing firefighters, thereby acting as a safety barrier between the firefighters and the fires.

2) There have been situations where firefighters have been trapped by such swiftly moving fires that airdrops were unable to come to their rescue, and although they sought protection beneath the fire-protection tents they carried, because of the intensity of the fires, this safeguard tragically proved inadequate to save them [2] [3]. However, if one had had batteries of catapults available, the catapult controllers could have oriented the trajectories of the water containers so that the waters they released came to a focus at the location of the threatening flames, thereby being able to extinguish them to such a degree that the firefighters would have been able to escape. Although with the introduction of a constant catapult protection, it is unlikely such a dire situation would ever arise.

3) The catapults could operate in conjunction with the airdrops. After the helicopters and planes have made their drops they will have to return to their water or retardant sources to refill their tanks. During the period they are away, the wildfires at these locations can flare up again. However, while they are away, the catapults, provided they have sufficient range, could be hurling water at these areas, thereby reinforcing the airdrops.

4) The catapults could be employed at times when flying is unsafe; indeed, there have been many tragic losses of flyers in such circumstances. The following reference is a recent example of the numerous tragedies associated with airdrops [4]. Thus the catapults could provide increased safety, not only for firefighters on the ground, but those serving from the air as well.

5) Another benefit is one that did not occur to me when I wrote the 2009 essay, but is nevertheless of utmost importance. It has been pointed out in the literature that wildfires pour billions of tons of $\mathrm{CO}_{2}$ into the atmosphere annually. Fire experts have estimated that the wildfires in northern California's wine country during October 2017 poured as much $\mathrm{CO}_{2}$ in one week as all of California's cars and trucks did in the course of one year! While according to National Ocean and Atmospheric Administration (NOAA) scientist, Pieter Tans, a very large very hot fire destroying 500,000 acres, could emit the same total amount of $\mathrm{CO}_{2}$ as six large coal-fired power plants in one year. For further discussion see the 2018 review article by Bob Berwyn [5]. More recently, in 2020, four million acres have burned in California, the most in a single year, and more than the last three years combined. Scaling up the above estimate by Pieter Tans, the total 
amount of $\mathrm{CO}_{2}$ produced could have amounted to that released by 48 large coal-fired power plants in one year! A few years earlier, in 2016, in Fort McMurray, Canada, nearly 1.5 million acres burned [6], possibly yielding the $\mathrm{CO}_{2}$ of 18 large coal-fired power plants in one year. For a worldwide view of the devastation caused by wildfires, with detailed emphasis on Canada [7], see the much-discussed book, containing numerous references, "Firestorm," by Edward Struzik [8]. He also emphasizes the beneficial side of wildfires [9] [10], while ignoring their large $\mathrm{CO}_{2}$ impact (see, e.g., his remarks on p. 230). It is clear from the above numbers that wildfires, because of their substantial $\mathrm{CO}_{2}$ emission, contribute significantly to global warming, and hence to climate change. But, as has been recognized and frequently commented on, climate change tends to increase the number and intensity of wildfires. Consequently, although it seems to be largely ignored in public discussions, one has a highly undesirable positive feedback loop, which can ultimately lead to an exponential growth of wildfires. To show this, let $N(t)$ be the number of wildfires at time $t$, and assume two sources to increase the number of fires: the first, coming from the background of global warming that produces $B$ wildfires per unit time, and the second, the feedback to the background coming from the $\mathrm{CO}_{2}$ produced by the wildfires that will be taken to be of the form $\kappa N(t)$, where $\kappa$ is the reciprocal of the time constant in the feedback loop. Then the rate of change of the number of wildfires at time $t$ is given by the following linear, first order differential equation:

$$
\mathrm{d} N(t) / \mathrm{d} t=B+\kappa N(t) .
$$

The solution to this equation is well-known, and with the initial condition. $N(0)=N_{0}$, it is given by:

$$
N(t)=\kappa^{-1} B\left(\mathrm{e}^{\kappa t}-1\right)+N_{0} \mathrm{e}^{\kappa t} .
$$

It will be noted that at very early times, $\kappa t \ll 1$, the number of wildfires increases only linearly, since $N(t)=\left(B+N_{0} \kappa\right) t+N_{0}$, but at much later times $\kappa t \gg 1$, the behavior is strictly exponential, $N(t)=\left(\kappa^{-1} B+N_{0}\right) \mathrm{e}^{\kappa t}$, as indicated in the preceding paragraph. It is well outside the scope of this work to give numerical estimates of these parameters, but the following references provide some information that could help in estimating them, see Nizur [11], and Schmalensee et al. [12]; although, it should be emphasized that these parameters are expected to vary considerably, from time to time, and place to place. In any case, one should want to extinguish these wildfires as quickly as possible so as to disrupt, or at least weaken, the above deadly positive feedback loop [13]. The introduction of catapults would clearly help to accomplish this, not only by helping to extinguish wildfires, but by helping to reduce global warming as well.

6) Another benefit concerns the current use of backfires that are controlled burns used by the firefighters to serve as a barrier to oncoming wildfires by depriving them of fuel [14]. The problem with this method is that these controlled burns also pour $\mathrm{CO}_{2}$ into the atmosphere, and hence also contribute to unwanted positive feedback. On the other hand, if one had a large number of catapults available, one could pour a sufficient amount of water on the selected areas 
so as to serve the equivalent of a controlled burn, while, importantly, avoiding the increase of $\mathrm{CO}_{2}$ into the atmosphere caused by the backfire.

7) Yet another benefit is the effective increase in firefighter power that the shortening of the extinguishing time brings. Thus, the firefighters fighting a fire at locality $\mathrm{A}$, when they have finished their work in a shorter time than with the present method, would become available sooner to assist with fighting a fire at locality $B$, thereby shortening the time to extinguish the fire at B by even a greater amount than that arising from the use of catapults. Thus one would have a cascade process in which there would be a continued increase in the number of firefighters available to fight the wildfires at different locations. Since in a large number of cases one has wildfires burning at many different locations, this effective increase in firefighting power would be significant.

8) Finally, as emphasized above, the shortening of the extinguishing time means a reduction in the number of homes and buildings that are damaged or destroyed, a reduction of losses to the environment, and, importantly, a reduction in the loss of life, not only human life, but the wildlife living in the woodlands. There is also the reduction in atmospheric pollution, whose effect on one's health can be significant, particularly that of children [15] [16], and that of the elderly and asthmatics [17] [18].

\section{Catapult Description}

Let us now turn to the catapults themselves, what form should they take? After reviewing various possibilities, I came to the conclusion that a practical choice would be to utilize a smaller version of the electromagnetic catapults that are at various stages of being used on aircraft carriers. The catapults should be of the sufficiently small length that they can fit on the back of a large truck, and mounted in such a way that they can track rapidly in elevation and azimuth as necessary. The aircraft catapults, known as EMALS in the U.S., [19] are used to launch aircraft that can weigh up to $40,000 \mathrm{~kg}$, whereas the water containers contemplated here would only weigh about $40 \mathrm{~kg}$. Consequently they could have much smaller electric power plants and much shorter recovery times. To estimate the electric power $P$ required for the catapult, the following simplifying assumptions will be made: air resistance will be neglected, and the catapult ramp will be set for maximum range. Hence one has:

$$
v^{2} / g=D,
$$

where $v$ is the speed with which the container leaves the ramp, $g$ is the acceleration of gravity, and $D$ is the maximum range. Now the kinetic energy imparted to the water container as it leaves the ramp is $M v^{2} / 2$, where $M$ is the mass of the water plus container. To give the container this kinetic energy, the power of the catapult will have been exerted through a time $\Delta t$, the interval of time the container is on the ramp. Assuming $\ell$ is the length of the ramp, the additional simplifying assumptions will be made: the air resistance to the containers carrying the water will be neglected, and the acceleration is uniform, so that 
$\Delta t=2 \ell / v$, and hence the energy supplied by the electric power is $P 2 \ell / v$. Setting this value equal to the above kinetic energy, upon neglect of the gravitational potential energy increase from the bottom to the top of the ramp, since it is small compared to the kinetic energy, $l \sqrt{2} / D$, since $\ell \ll D$, one has $P=M v^{3} / 4 \ell$. So finally, upon replacing $v$ with its value from (3), one has

$$
P=\frac{M}{4 \ell}(g D)^{3 / 2} .
$$

Before estimating the power $P$, it is helpful to see how it could be obtained. Assume the catapult is mounted on a truck, and the water containers carried on another truck that could accompany the catapult truck. There would also be a simple machine that would transfer the water containers from the container truck to catapults on the catapult truck. Assume further that the engines of the two trucks are the same, and there combined power when the trucks are stationary would be used to power the electromagnetic catapult. To get a numerical estimate of $P$, assume $D=0.5 \mathrm{~km}, \ell=5 \mathrm{~m}, M=40 \mathrm{~kg}$, and with $g=9.8 \mathrm{~ms}^{-2}$, one obtains:

$$
P=686 \mathrm{~kW}=920 \mathrm{hp} \text {. }
$$

So that each engine would have to be able to deliver $460 \mathrm{hp}$. This is well within the range of large truck engines that run in some cases as high as $570 \mathrm{hp}$. In other words, the engines could be "off-the-shelf," thereby reducing costs. Even if we allow another, say, 10 percent in horsepower to cover transference, friction, and air resistance losses, it would only boost the largetruck engines to $506 \mathrm{hp}$. Hence the truck engines would still be in the range of off-the-shelf engines, and therefore would not entail large additional costs. However, I found no references to the electromagnetic device of the required energy that would supply the needed electromagnetic force to drive the containers up the ramp; this will probably require special development.

To be able to attack wildfires at greater distances than $0.5 \mathrm{~km}$, there are several possibilities. The first would be to make use of a creeping barrage, sending water ahead of the firefighters on the ground, and then move the battery or batteries slowly forward. A second possibility would be to utilize more powerful catapults, although this would require much larger horsepower engines that would no longer be "off-the-shelf," and hence would entail higher costs. A third possibility would be to have permanent sites distributed throughout the forest areas, with roads leading to these sites, so that the catapult batteries need not be kept there, but could be driven there when needed. Although to be sure, one could have fixed catapult batteries in some areas.

A major problem is the composition of the water containers. They must not only be able to withstand the launch acceleration, but after being opened to release the water, which may possibly be achieved by means of some small explosive device, they should not come down in fragments that would contaminate the environment, nor contribute to the fires themselves. One possibility would be to make them of some ceramic material. In any case, the composition of the containers would be one of the many projects the contemplated research and 
development program would investigate. Also, part of this project would be the determination of how and when the containers would be opened to release their water content. In some cases, this could be done manually by an observer at the catapult position, but in other cases, it could be done by an automatic timing device attached to the container that would be set upon release.

\section{Catapult Water Delivery Capability, and Comparison with Airdrops}

It is interesting to compare the amount of water delivery by the proposed catapult system with airdrop water and/or fire retardant delivery [20]. In the above simplified model, the containers contain 40 liters of water, since they have a weight of $40 \mathrm{~kg}$, where, for simplicity, the weight of the container and explosive device has been ignored, since together they would weigh much less than a kilogram. Since for the above model, $v=70 \mathrm{~ms}^{-1}$, and hence $\Delta t=0.14$ seconds, and allowing several seconds for recovery time and transfer time, one should be able to launch a container every 4 seconds. Hence, a single catapult could deliver 600 $\mathrm{L}$ of water a minute, and therefore a 10 catapult battery, $6000 \mathrm{~L}$ a minute. A large helicopter, such as the Sikorsky CH-53 "Super Stallion" has a bucket capacity of approximately $7600 \mathrm{~L}$, so the catapult battery could exceed that in 1.3 minutes. A modified McDonnell Douglas DC-10 can carry up to 45,400 L of fire retardant. The catapult battery could exceed that by delivering $48,000 \mathrm{~L}$ in 8 minutes. While in 12.5 minutes it could drop $75,000 \mathrm{~L}$ on the fire, which exceeds the $74,000 \mathrm{~L}$ that a 747 supertanker can deliver. However, these comparisons must be balanced by the fact that the airdrops occur in a matter of seconds, in contrast with the much longer times required by the catapults, and hence the catapult drops act as supplementary back-ups until the airplanes and helicopters can refill their tanks and return. Also, importantly, the catapults can be used to substantially wet down areas before the wildfires reach them, thereby reducing the need for controlled burns, and, as indicated above, they can serve to protect the firefighters as they advance on the wildfires.

\section{Conclusion}

There are numerous other questions that arise in conjunction with the proposed catapult systems, but I believe the above discussion is sufficient to show the desirability of building prototypes and testing them. If the tests prove successful, the catapult systems could help to reduce the worldwide devastation and atmospheric pollution the wildfires are causing, and thereby improve the quality of life for everyone, including wildlife.

\section{Conflicts of Interest}

The author declares no conflicts of interest regarding the publication of this paper.

\section{References}

[1] Tangherlini, F.R. (2009) A Proposed New Weapon to Fight Wildfires. Community 
Essay Diego Union Tribune.

[2] Coe, J. and Merrill, L. (2013) 19 Firefighters Dead in Yarnell Hill Fire. The Arizona Republic.

[3] Dickman, K. (2015) On the Burning Edge: A Fateful Fire and the Men Who Fought It. Ballentine Books, New York.

[4] Foskett, J. (2020) Two Firefighting Aircraft Collided While Battling a Wildfire in Nevada. Fire Research, 1.

[5] Berwyn, B. (2018) How Wildfires Can Affect Climate Change (and Vice Versa). https://insideclimatenews.org/news/23082018/

[6] Asher, D. (2017) Inside the Inferno: A Firefighter's Story of the Brotherhood That Saved Fort McMurray. Simon and Schuster Canada, Toronto.

[7] Hogg, E.H., Brandt, J.P. and Kochtubajda, B. (2002) Growth and Dieback of Aspen Forests in Northwestern Alberta, Canada in Relation to Climate and Insects. Canadian Journal of Forest Research, 32, 823-832. https://doi.org/10.1139/x01-152

[8] Struzik, E. (2019) Firestorm: How Wildfire Will Shape Our Future. Island Press, Washington.

[9] Barrett, S. and Arno, S.F. (1982) Indian Fires as an Ecological Influence in the Northern Rockies. Journal of Forestry, 80, 647-651.

[10] Lewis, H. (1982) A Time for Burning. Boreal Institute of Northern Studies. University of Alberta, Edmonton.

[11] Nazur, J. (2019) Mathematical Model for $\mathrm{CO}_{2}$ Emission Reduction to Slow and Reverse Global Warming. Global Warming and Climate Change, Intech Open, 15.

[12] Schmalensee, R., Stokee, T.M. and Judson, R.A. (1998) World Carbon Dioxide Emission: 1950-2050. Review of Economics and Statistics, 80, 15-27.

https://doi.org/10.1162/003465398557294

[13] Tangherlini, F.R. (2019) How to Put Out a Fire? Letter. London Review of Books, 41,5 .

[14] Bradstock, R.A., Bedward, M., Kenny, J. and Scott, J. (1998) Spatially-Explicit Simulation of the Effect of Prescribed Burning on Fire Regimes and Plant Extinction in Shrub Lands Typical of South-Eastern Australia. Biological Conservation, 86, 83-95. https://doi.org/10.1016/S0006-3207(97)00170-5

[15] Kunzil, N., Wu, J., Gauderman, J., et al. (2006) Health Effects of the 2003 Southern California Wildfires on Children. American Journal of Respiratory and Critical Care Medicine, 174, 1221-1228. https://doi.org/10.1164/rccm.200604-519OC

[16] Delfino, R.J., Brummel, S., Wu, J., et al. (2009) The Relationship of Respiratory and Cardiovascular Hospital Admissions to the Southern California Wildfires of 2003. Occupational and Environmental Medicine, 66, 189-197.

https://doi.org/10.1136/oem.2008.041376

[17] Reid, C.E., Jerrett, M., Tager, I.B., et al. (2016) Differential Respiratory Health Effects from the 2008 Northern California Wildfires: A Spatio-Temporal Approach. Environmental Research, 150, 227-235. https://doi.org/10.1016/j.envres.2016.06.012

[18] Liu, J.C., et al. (2014) A Systematic Review of the Physical Health Impacts from Non-Occupational Exposure to Wildfire Smoke. Environmental Research, 136, 120-132. https://doi.org/10.1016/j.envres.2014.10.015

[19] https://en.wikipedia.org/wiki/Electromagnetic-Aircraft-Launch-System

[20] https://en.wikipedia.org/wiki/Aerial-firefighting 